https://doi.org/10.48009/1_iis_2006_346-351

\title{
MANAGEMENT INFORMATION SYSTEMS: ASSESSING STUDENT PLACEMENT \& PERFORMANCE
}

\author{
Sharon Paranto, Northern State University, parantos@northern.edu \\ Hillar Neumann, Northern State University, hnj@northern.edu
}

\begin{abstract}
This paper describes the process used at one university in utilizing a pre-/post-test to assess the level of learning that took place in an MIS course that was incorporated into the business core curriculum and in developing a corresponding course-level assessment report for accreditation purposes. It is an extension of previous research that was conducted to evaluate the tools utilized in assessing student information systems competencies in a rapidly-changing global economy. As the study was extended and post-test scores were analyzed, the MIS Department found that the pre-/post-test process was not only useful in providing a measure of the level of learning that took place, but also in providing evidence that the intended outcomes of the technology component of the business core were achieved.
\end{abstract}

Keywords: Assessment, Placement Testing, Accreditation, IS Assessment

\section{INTRODUCTION}

MIS 205, Advanced Computer Applications, recently became one of the core courses required of all business majors at our university. The MIS 105 course, Introduction to Computers, is a pre-requisite to the advanced course. However, many students enter college with technical knowledge and skills equivalent to those expected of a student completing MIS 105. Therefore, the university needed a method by which students could be placed directly into the advanced course, if they had the knowledge and skills necessary for success in the MIS 205 course. A series of hand-on, skills-based tools are available for accomplishing this, but because of both financial and logistic issues, these were not deemed feasible. Therefore, the Management Information Systems department developed an in-house placement test which has been used to place students into either MIS 205 or its pre-requisite, MIS 105, based on each student's testable knowledge and skills.

A second concern was how to assess the technical components of the business core in order to 1) satisfy accreditation requirements and 2) determine if intended outcomes were achieved. Often, standardized exit exams that measure student learning include sub-scores for core business areas, such as accounting, economics, finance, marketing, management, etc., but few include a measure of knowledge and skills related to management information systems (MIS). Standardized computer exams exist, but many are more technical (computer science) in nature than one finds in an MIS curriculum. In addition, accrediting bodies, both nationally and internationally, are moving beyond focusing on program assessment to an emphasis on course-level assessment.

It was decided that the placement test could also be used as a tool for course-level assessment. However, the department soon discovered that for accreditation, it was not sufficient to simply indicate that learning took place. The concern was whether "sufficient" learning took place to prepare students for the business world. The department decided that test results could be used to provide a measure of the level of learning that took place and could, in turn, provide accrediting agencies with evidence that the intended outcomes of the applicable courses were achieved. The data that have been collected to date and the corresponding statistical analyses of the data, findings, and conclusions are summarized in this paper.

\section{TESTING METHOD}

Technology skills have altered the landscape of classroom learning; however, research in the field of student technology literacy skills is very limited [4]. The method for assessing these skills is undergoing continual change. The major difficulty in developing the placement test at our university was in determining which format of testing would fit into the university budget, time-constraints, and other limiting factors, while still achieving our goal of assessing technological skills and competencies.

A review of the literature reveals that a great deal of debate exists over the validity of using multiplechoice questions to assess technology skills [3]. However, proponents indicate that students benefit from the process of problem solving through 
multiple-choice. Cook-Sather [1] states that by exploring a range of answers, students develop critical thinking skills. Students have the option of multiple answers and multiple ways to develop critical thinking to choose the right answers. Sharif [5] asserts that multiple-choice testing is the superior assessment tool because it is closer to real life. He states that with multiple-choice questions, no credit is given for partial answers, and therefore multiplechoice is the most reliable tool for assessing critical thinking skills

After investigating various options, our university made the decision to utilize a multiple-choice exam to assess student knowledge and skills and place students into the appropriate technology-related courses, primarily because of logistics and financial issues. To start the test construction, a large number of questions related to the competencies that students are expected to acquire in MIS 105 and MIS 205 were selected from a variety of sources. The test was developed based on the technical competencies that the business school deemed necessary for success in the business world.

The exam included questions associated with word processing, spreadsheets, databases and database management, presentation software, and the Internet, as well as computer concepts. Many of the questions were designed to assess whether students understood how to utilize the software effectively, rather than whether they had the ability to regurgitate a definition.

For instance, to assess a student's knowledge and understanding of word processing, the following question might be utilized:

If a student presses Ctrl+End to move the insertion point to the end of his or her document, then clicks the Underline button on the Formatting toolbar,

a. the entire document will be underlined.

b. the next word typed will be underlined, then text will revert to normal.

c. whatever text is typed from that point forward will be underlined, until the Underline command is turned off.

d. None of the above

Similarly, questions were included to assess whether students had an understanding of the Internet, such as:
Information about tobacco use that has been found on a personal homepage on the Internet

a. is checked for accuracy by an impartial third party.

b. may include statistics that were made up by the author.

c. must coincide with information released by the American government.

d. Only A and C

It was felt that students with a good understanding of the Internet would be able to answer this question correctly. Most students who had completed the Intro course were able to answer it correctly, especially since most had created their own website as part of a class project, but the majority of the incoming students who had not yet taken a college-level computer course believed that if they found information on the Internet, it could be cited as a valid source of information, regardless of the website utilized.

Some of the spreadsheet questions related to simple formulas, as well as slightly more complicated formulas, such as the IF statement. In addition, questions were utilized in determining if the student had a good understanding of both absolute and relative addressing when copying formulas.

Sample questions follow:

The formula works behind the scenes to tell the computer to subtract the number in cell B5 from the number in cell $B 4$. [Note: Sample budget utilized]
a. $=\mathrm{B} 5-\mathrm{B} 4$
b. $=\mathrm{B} 4-\mathrm{B} 5$
c. $=\mathrm{B} 4(\mathrm{~B} 5)$
d. B4-B5

The IF function $=I F(G 3<=\$ E \$ 3, G 3 * 1.2$, G3*1.4) assigns to the cell if the logical test is true.
a. $\mathrm{G} 3 * 1.4$
b. $\mathrm{G} 3 * 1.2$
c. $\$ \mathrm{E} \$ 3$
d. 0 (zero)

If the formula $=B 4 * C 4$ is in cell $D 4$, the formula assigned to cell D5 when the formula is copied is
a. $=\mathrm{B} 4 * \mathrm{C} 4$
b. $=\mathrm{A} 4 * \mathrm{~B} 4$
c. $=\mathrm{B} 5 * \mathrm{C} 5$
d. $=\mathrm{A} 5 * \mathrm{~B} 5$ 
When a formula containing the cell reference is copied to another cell, the row reference and column reference remain the same.
a. $\$ \mathrm{~B} \$ 16$
b. $B \$ 16$
c. $\$ \mathrm{~B} 16$
d. B16

Similar questions relating to databases and presentation software were incorporated into the exam, as well.

\section{DATA COLLECTION AND EXAM SELECTION CRITERIA (A TEST OF THE TEST)}

The first draft of the exam contained 100 questions and was given to all sections of MIS 105 and 205 in the spring 2005 semester, in order to "test the test." The results of this pre-test were used to select the test questions to be included in the final version of the placement exam.

The exam was administered using the course management tool, WebCT. The exam selection criteria's goal was to include questions in the final version of the exam that would differentiate between those students who understood the concepts and those students who did not. In order to choose the appropriate questions, information provided by WebCT and other statistical packages were utilized. WebCT reports the "discrimination" statistic which, when combined with other statistical information, assists in determining which questions differentiate between those students who have the required understanding of the material and those who do not. (Refer to WebCT [6] for more information on the formula and process used to determine the discrimination value.)

Table 1 reports the summary statistics for a sample of questions, which illustrates the process of question selection [2]. In evaluating the questions, it was decided that Question 1 was an appropriate question, because $76 \%$ of all students taking the exam answered this question correctly, $94 \%$ of the students who scored in the upper $25 \%$ of the group on the exam answered it correctly, and only $54 \%$ of the students who scored in the lower $25 \%$ of the group on the exam answered it correctly. It has a "discrimination" value of 0.40 , which indicates a high level of discrimination between the students who understood the concepts and those who did not.
Table 1. Analysis of Questions - Sampling

\begin{tabular}{|c|c|c|c|c|c|c|}
\hline \multirow{3}{*}{$\frac{\text { Quest }}{\underline{\text { ion }}}$} & \multicolumn{3}{|c|}{ \% Correct of: } & \multirow{3}{*}{$\frac{\frac{\text { Disc }}{\text { rimin }}}{\underline{\text { ation }}}$} & \multirow{3}{*}{$\begin{array}{l}\text { Score } \\
\text { Mean }\end{array}$} & \multirow{3}{*}{ SD CV } \\
\hline & Whole & Uppe & Lowe & & & \\
\hline & Group & $25 \%$ & $25 \%$ & & & \\
\hline Q1 & 76 & 94 & 54 & 0.40 & $76.4 \%$ & $42.655 .8 \%$ \\
\hline $\mathrm{Q} 2$ & 53 & 91 & 13 & 0.50 & $53.4 \%$ & $50.193 .8 \%$ \\
\hline Q3 & 89 & 89 & 81 & 0.13 & $89.2 \%$ & $31.235 .0 \%$ \\
\hline Q4 & 98 & 100 & 94 & 0.47 & $98.6 \%$ & $11.611 .8 \%$ \\
\hline
\end{tabular}

Table 1 also reports the coefficient of variation (CV), which is computed using the standard deviation relative to the mean. The higher this value the greater is the standard deviation relative to the mean and thus the greater the question's ability to discriminate. Similarly, Question 2 has a high discrimination value and shows large differences between the overall group percentage and the upper $25 \%$ and lower $25 \%$ results; it also has a high coefficient of variation. This was deemed to be a good question.

Conversely, Question 3 shows a low discrimination value, a low coefficient of variation, and little difference among the percentage of all students answering the question correctly, the upper $25 \%$, and the lower 25\%. Question 4 shows a high discrimination value, but has a very low coefficient of variation, and as the scores indicate, almost everyone answered it correctly. Both Questions 3 and 4 were removed from the final version of the exam. This same process was used in evaluating all 100 questions on the pre-test of the placement exam.

After each question was evaluated and nondiscriminatory questions were removed, the final version of the exam became the placement test for MIS 105/205 and was given to all incoming students majoring in business. (All other students were under the program requirements from a prior catalog, in which students were required to complete MIS 105.) A predetermined cut-off score of $70 \%$ was established to place students into the appropriate MIS course. This exam also became the course-level pretest and the post-test for all sections of MIS 105 and 205 in the fall 2005 semester.

The subject pool for this study was all students enrolled in either MIS 105 or MIS 205. There was a combination of students who were enrolled in MIS 205: those students who "placed" into 205; those students who had completed 105 and elected to take 205; and those students who had transfer credit for 105 and were required, under the new program, to take 205. Similarly, some students enrolled in MIS 105 were "placed" into it; others were students 
who were required, under the old program, to complete 105.

\section{FINDINGS}

The pre-test analysis that follows is a result of prior research [2]. It is followed by post-test results that were statistically compared with the pre-test data, and with intended outcomes that were established by the department, as part of the current research.

\section{Pre-Test Results}

Descriptive statistics showing a comparison of the MIS 105 group and the MIS 205 group are included in Table 2 [2].

Table 2. MIS 105/205 Pre-Test Sample Descriptive Statistics

\begin{tabular}{|c|c|c|}
\hline & $\underline{\text { MIS } 105}$ & MIS 205 \\
\hline Sample size (n) & 129 & 22 \\
\hline Mean & 0.498 & 0.711 \\
\hline Standard deviation & 0.119 & 0.112 \\
\hline Minimum & 0.233 & 0.417 \\
\hline Maximum & 0.800 & 0.883 \\
\hline 1st quartile & 0.417 & 0.621 \\
\hline Median & 0.500 & 0.742 \\
\hline 3rd quartile & 0.583 & 0.783 \\
\hline Mode & 0.583 & 0.783 \\
\hline
\end{tabular}

The number of students enrolled in MIS 205 (22) is much smaller than the number enrolled in MIS 105 (129). This is because MIS 205 was the required course only for those students who were enrolled for the first time in fall 2005. This number will gradually increase as more students enroll under the revised curriculum, which requires MIS 205 as part of the business core.

The mean percentage score, reported in Table 2, for the MIS 105 students is 0.498 (49.8\%), with a standard deviation of 0.119 , whereas the mean percentage score of the MIS 205 students is 0.711 $(71.1 \%)$, with a standard deviation of 0.112 .

Table 3. t-Test of Difference in Pre-Test Means

\begin{tabular}{|c|c|c|}
\hline MIS 205 & MIS 105 & \\
\hline 0.711 & 0.498 & Mean \\
\hline 0.112 & 0.119 & Standard Deviation. \\
\hline 22 & 129 & $\mathrm{n}$ \\
\hline \multicolumn{3}{|c|}{ Calculated $\mathrm{t}=7.84$} \\
\hline
\end{tabular}

Table 3 reports the $t$-statistic for difference in pre-test means for MIS 105 and MIS 205 [2]. The t-statistic of 7.84 indicates there is a statistically significant difference at a $1 \%$ level between the MIS 105 and MIS 205 means. This lends credence to the assertion that the placement test was effective in placing students into the appropriate course.

\section{Pre-/Post-Test Analysis}

When the post-test was administered, the number of students included in the data analyses decreased considerably. First, one instructor chose not to administer the post-test in his sections, which limited the post-test data that was collected. Secondly, some students either dropped the class or were not present when the post-test was administered. Therefore, the number of students who completed both the pre-test and the post-test was reduced to 64 students in MIS 105 and 17 students in MIS 205. Subsequent statistical analyses only include those students who completed both the pre- and post-tests.

Table 4 reports the summary statistics for the preand post-tests for both MIS 105 and MIS 205. The data indicate that the mean score for the MIS 105 students who completed both the pre- and post-test increased from $0.509(50.9 \%)$ to $0.640(64.0 \%)$, while the mean score of the MIS 205 students who completed both exams increased from 0.714 (71.4\%) to $0.818(81.8 \%)$.

Table 4. MIS 105/205 Pre-/Post-Test Descriptive Statistics

\begin{tabular}{lrrrr}
\hline & \multicolumn{2}{c}{ MIS105 } & \multicolumn{2}{c}{ MIS205 } \\
& \multicolumn{2}{c}{ Posttes } & \multicolumn{2}{c}{ Posttes } \\
& Pretest & \multicolumn{1}{c}{ t } & Pretest & \multicolumn{1}{c}{ t } \\
\hline $\mathrm{n}$ & 64 & 64 & 17 & 17 \\
Mean & 0.509 & 0.640 & 0.714 & 0.818 \\
Sample variance & 0.014 & 0.021 & 0.015 & 0.015 \\
Standard error & 0.015 & 0.018 & 0.029 & 0.029 \\
Minimum & 0.283 & 0.333 & 0.417 & 0.483 \\
Maximum & 0.800 & 0.917 & 0.883 & 0.983 \\
Median & 0.517 & 0.658 & 0.767 & 0.850 \\
\hline
\end{tabular}

The box plots in Figure 1 illustrate the distribution of the percentage scores on the pre-tests and post-tests in MIS 105 and in MIS 205 for the students who completed both exams. 

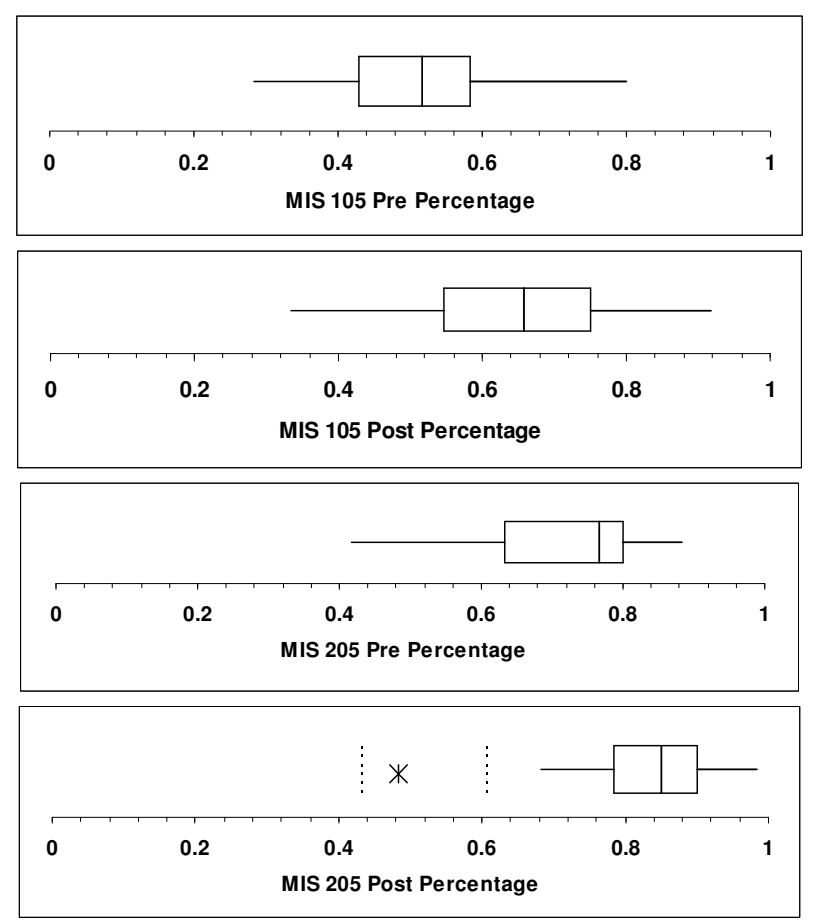

Figure 1. Pre-/Post-Test Box Plots

Similarly, the chart in Figure 2 provides a visual imagery of the progression of means, starting with the MIS 105 pre-test and post-test means, followed by the MIS 205 pre-test and post-test means.

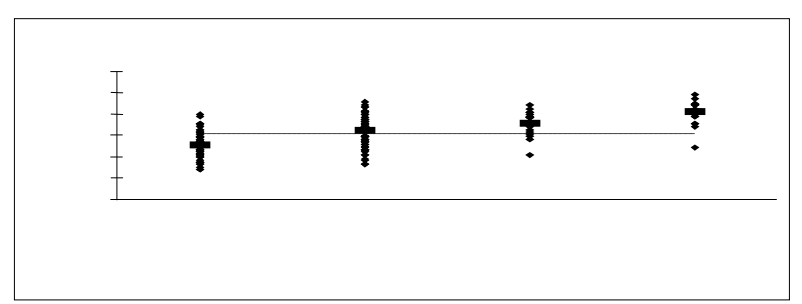

Figure 2. Comparison of MIS $105 \& 205$ Pre \& Post Percentage

Statistical tests (calculated t-statistic) comparing the pre-test scores and the post-test scores for MIS 105 and MIS 205 are reported in Table 5.

Table 5. Hypothesized Test - Pre-/Post-Test Paired Observations

\begin{tabular}{lrr}
\hline & MIS 105 & MIS 205 \\
\cline { 2 - 3 } Hypothesized Difference & 0 & 0 \\
Mean Post Percentage & 0.640 & 0.818 \\
Mean Pre Percentage & 0.509 & 0.714 \\
Standard Deviation & 0.121 & 0.06 \\
Standard Error & 0.015 & 0.015 \\
$\mathrm{n}$ & 64 & 17 \\
\hline Calculated t & 8.67 & 7.11 \\
\hline
\end{tabular}

As indicated by the calculated t of 8.67 for MIS 105 and 7.11 for MIS 205, there is a statistically significant difference in the pre-test and post-test means for each course, lending credence to the assertion that learning took place.

\section{Outcomes}

It is important to demonstrate that the intended outcomes established for the course have been achieved. The following outcome was established by the department: at least $75 \%$ of the students completing MIS 205 will score at or above $75 \%$ on the MIS technology-related post-test. Table 6, below, provides a breakdown of the post-test percentage scores for MIS 205. As the data indicate, $76.47 \%$ of the students who completed the post-test scored at or above $75 \%$ on the exam, which satisfies the criteria established by the department.

Table 6. Outcomes Assessment

\begin{tabular}{lccc}
\hline Score & \# Students & Percentage $^{1}$ & Cumulative $^{2}$ \\
\hline $95-100 \%$ & 2 & $11.76 \%$ & $11.76 \%$ \\
$90-<95 \%$ & 3 & $17.65 \%$ & $29.41 \%$ \\
$85-<90 \%$ & 4 & $23.53 \%$ & $52.94 \%$ \\
$80-<95 \%$ & 2 & $11.76 \%$ & $64.71 \%$ \\
$75-<80 \%$ & 2 & $11.76 \%$ & $76.47 \%$ \\
$70-<75 \%$ & 2 & $11.76 \%$ & $88.24 \%$ \\
$0-<70 \%$ & 2 & $11.76 \%$ & $100.00 \%$ \\
\hline Totals & 17 & $100.00 \%$ & \\
\hline
\end{tabular}

${ }^{\mathrm{T}}$ The Percentage column indicates the percentage of students with scores in the Score range indicated

${ }^{2}$ The Cumulative column indicates the percentage of students with scores greater than or equal to the Score range indicated.

Data will continue to be collected and evaluated from semester to semester, to evaluate whether student scores continue to meet the established outcomes. Because of the small number of students (17) completing the MIS 205 post-test, the scores will have to be monitored closely during future semesters, but the number of students completing the course should increase significantly as more students declare a business major under the new guidelines that require MIS 205. Also, due to the ever-changing nature of technology, the exam will need to be evaluated and revised on an annual basis, as the content of the courses continue to evolve to keep pace with technology and the ever-changing needs of the business environment. 


\section{CONCLUSION}

The MIS department concluded that the placement test has been effective in placing students into the appropriate course. Additionally, the post-test scores have been useful in providing a measure of the level of learning that took place and evidence that the intended outcomes of the technology component of the business core were achieved. The pre-/post-test process will continue to be used to evaluate the MIS component of the business core curriculum. The results will be incorporated into the annual assessment report and will be utilized in modifying the course content and/or the corresponding pedagogy and/or the test itself. The next step will be to expand the process by developing and implementing pre-/post-test scenarios for other courses in the business core.

\section{REFERENCES}

1. Cook-Sather, A. (1997). Making Connections: The Brain and the Creation of Optimal Learning Opportunities for Students. (serendip.brynmawr.edu/ sci_edu /cook-sather.html)

2. Paranto, S. \& Neumann, H. (2006). Evaluating the tools utilized in assessing student information systems competencies in a rapidly-changing global economy. International Academy of Business and Public Administration Disciplines Winter Conference Proceedings, 3(1), 421-429.

3. Paranto, S. \& Shillington, L. (2005). Is it possible to assess information skills using a multiple-choice exam? Article abstract from the Proceedings/Program of the ISECON 2005 22nd Annual Information Systems Education Conference, 27-28.

4. Schuh, A. V. (2004). Equity and Technology Literacy in the Mid-Atlantic Region (www.temple.edu/mar tec/assistance/pd/schuh_paper_web.pdf).

5. Sharif, S. (2005). Physics tweaks testing methods at Georgia Tech. University Wire, Atlanta.

6. WebCT: Learning Without Limits. (2005). WebCT, Inc. (www.webct.com). 